\title{
Green Synthesis, Characterization of Gold Nanomaterials using Gundelia tournefortii Leaf Extract, and Determination of Their Nanomedicinal (Antibacterial, Antifungal, and Cytotoxic) Potential
}

\author{
Cumali Keskin (D), ${ }^{1,2}$ Ayşe Baran, ${ }^{3}$ Mehmet Furat Baran,, ${ }^{1,2}$ Abdulkerim Hatipoğlu, 4 \\ Mehmet Tevfik Adican, ${ }^{5,6}$ Mehmet Nuri Atalar, ${ }^{7}$ Irada Huseynova, ${ }^{8}$ \\ Rovshan Khalilov $\mathbb{D}^{2,6,9,10}$ Elham Ahmadian $\mathbb{D}^{11},{ }^{11}$ Ömer Yavuz, ${ }^{12}$ Sevgi İrtegün Kandemir, ${ }^{13}$ \\ and Aziz Eftekhari ${ }^{14,15,16}$ \\ ${ }^{1}$ Department of Medical Services and Techniques, Vocational School of Health Services, Mardin Artuklu University, Mardin, Turkey \\ ${ }^{2}$ Joint Ukraine-Azerbaijan International Research and Education Center of Nanobiotechnology and Functional Nanosystems, \\ Drohobych, Baku, Azerbaijan, Ukraine \\ ${ }^{3}$ Department of Biology, Institute of Graduate Education, Mardin Artuklu University, Mardin, Turkey \\ ${ }^{4}$ Department of Nutrition and Dietetics, Faculty of Health Sciences, Mardin Artuklu University, Mardin, Turkey \\ ${ }^{5}$ Department of Electricity and Energy, Vocational School, Mardin Artuklu University, Mardin, Turkey \\ ${ }^{6}$ Department of Biophysics and Biochemistry, Baku State University, Baku, Azerbaijan \\ ${ }^{7}$ Department of Nutrition and Dietetics, Faculty of Health Sciences, Igdir University, Igdir, Turkey \\ ${ }^{8}$ Institute of Molecular Biology \& Biotechnologies, Azerbaijan National Academy of Sciences, 11 Izzat Nabiyev, \\ Baku 1073, Azerbaijan \\ ${ }^{9}$ Institute of Radiation Problems, National Academy of Sciences of Azerbaijan, Baku, Azerbaijan \\ ${ }^{10}$ Drohobych Ivan Franko State Pedagogical University, Drohobych, Ukraine \\ ${ }^{11}$ Kidney Research Centre, Tabriz University of Medical Sciences, Tabriz, Iran \\ ${ }^{12}$ Department of Chemistry, Faculty of Science, Dicle University, Diyarbakir, Turkey \\ ${ }^{13}$ Department of Medical Biology, Dicle University, Faculty of Medicine, Diyarbakir, Turkey \\ ${ }^{14}$ Health Innovation and Accelerations Center, Tabriz University of Medical Sciences, Tabriz 51664, Iran \\ ${ }^{15}$ Stem Cell Research Centre, Tabriz University of Medical Sciences, Tabriz, Iran \\ ${ }^{16}$ Department of Pharmacology \& Toxicology, Tabriz University of Medical Sciences, Tabriz, Iran
}

Correspondence should be addressed to Cumali Keskin; ckeskinoo@gmail.com and Aziz Eftekhari; ftekhari@ymail.com

Received 25 November 2021; Revised 5 February 2022; Accepted 10 February 2022; Published 27 February 2022

Academic Editor: Dong Kee Yi

Copyright ( $(2022$ Cumali Keskin et al. This is an open access article distributed under the Creative Commons Attribution License, which permits unrestricted use, distribution, and reproduction in any medium, provided the original work is properly cited.

Introduction. Fighting against cancer and antibiotic resistance are important challenges of healthcare systems, and developing new treatment methods has become the most concentrated area of researchers. Method and Materials. Green synthesis, characterization, and some biological activities of gold nanomaterials (AuNPs) obtained with Gundelia tournefortii (kenger) leaf extract were investigated in this study. Fourier scanning electron microscope, UV-visible spectrophotometer, Fourier transform infrared spectroscopy, energy-dispersive X-ray spectrophotometer, X-ray diffraction diffractometer, transmission electron microscope, and Zetasizer instrument data were used to elucidate the structures of nanoparticles. Results. The maximum surface plasmon resonance was observed at $532.15 \mathrm{~nm}$ after 1 hour. With the powder XRD model, the mean cubic crystallite size was determined as $23.53 \mathrm{~nm}$. It was observed that the shapes of the obtained AuNPs were spherical, and the dimensions were 5-40 $\mathrm{nm}$ and 
hexagonal. Surface charges $(-27 \mathrm{mV})$ and average size $(365.3 \mathrm{~nm})$ of gold nanoparticles were measured with a zeta analyzer. Conclusion. The suppressive effects of AuNPs on the growth of pathogenic microorganisms and healthy and cancer cell lines were determined using the MIC and MTT methods, respectively.

\section{Introduction}

Nanobiotechnology is a new promising field seeing the design, manipulation, and practice of nanoparticles (NPs) to produce new solutions needed in many fields [1]. The unique properties of nanoparticles rely on monodispersed size and surface morphology; various shapes and sizes of nanomaterials can be obtained by changing the synthesis stage $[2,3]$. Nanoparticles are widely produced in the industry by physical and chemical methods [4]. Nowadays, instead of conventional methods, it is more preferred to produce nanoparticles with fast and low-cost green synthesis procedures that do not use toxic solvents do not pollute the environment [5]. In this context, scientific studies have focused on synthesizing these nanomaterials from biological sources such as plants, algae, seaweeds, viruses, bacteria, and fungi $[6,7]$.

In nanoparticle studies, zinc [8], gold [9], silver [10], nickel [11], iron [12], platinum [13], and selenium [14] salts are metals that have been extensively studied in nanoparticle synthesis. Especially, AuNPs are widely preferred in biomedical and imaging applications. One of the important reasons of AuNPs is preferred in biological applications that can be easily synthesized and have the least toxicity compared to other metals [1].

Due to the unaware use of drugs and the increase of antibiotic resistance in pathogenic microorganisms, incidence of infectious diseases and drug consumption has increased significantly worldwide [15]. Researchers have reported that metallic nanoparticles can be an alternative to conventionally used antimicrobial agents [16-20].

On the other hand, today, fighting cancer with different varieties, which is very difficult to treat and often insufficient, and developing new treatment methods have become the most concentrated area of researchers [15]. In this context, researches are carried out on the anticancer properties of metal nanoparticles [14]. While metal nanoparticles are being evaluated as antimicrobial and anticancer agents, they are also being evaluated in diagnostic, cell labelling, biomarker, drug delivery, cancer treatment, and water treatment applications [21-24].

Gundelia tournefortii (GT), a member of the Asteraceae family, is an artichoke-like medicinal plant that grows in countries such as Iran, Cyprus, Egypt, Jordan, Turkey, Azerbaijan, and Turkmenistan [25, 26]. All parts of GT have been used both as a food source and as a medicinal plant since ancient times [27]. It has been reported that it was used in the treatment of many diseases in traditional folk medicine [25-27]. The size of AuNPs is smaller compared to that of nanoparticles synthesized from metals such as copper, titanium, zinc, iron, and silver. These properties facilitate their passage through cell membranes. For this reason, they show stronger antimicrobial, cytotoxic, and anti-inflammatory activity. This is the first study to show that the AuNPs were synthesized by an environmentally friendly way using GT leaf extract. In this study, the synthesis, characterization, and anticancer and antimicrobial potential of AuNPs were evaluated in detail. The obtained results will make a significant contribution to the literature.

\section{Material and Method}

\subsection{Material}

2.1.1. Herbal Material. GT used in the study was collected from Diyarbakır (Karacadağ/Yiğityolu village) in MarchApril. It is located at $37^{\circ} 52^{\prime} 19^{\prime \prime}$ north latitude and $39^{\circ} 52^{\prime}$ $28^{\prime \prime}$ east longitude at an altitude of 962 masl. Taxonomically identified specimens (Gundelia tournefortii L.) were stored in the Herbarium of Mardin Artuklu University (2021-6MAU), Mardin, Turkey.

2.1.2. Chemicals and Reactive. Tetrachloroauric acid $\left(\mathrm{HAuCl}_{4} \cdot 3 \mathrm{H}_{2} \mathrm{O}\right)$ (Alpha Aesar), Mc Farland solution (0.5), RPMI medium, Mueller Hinton Broth, fluconazole, vancomycin, and colistin antibiotics (Sigma Aldrich, USA) used in the study were commercially available.

2.1.3. Microorganisms and Cell Lines Used in Biological Assay. Gram-positive strains (B. subtilis ATCC 11774; S. aureus ATCC 29213), gram-negative (E. coli ATCC 25922; P. aeruginosa ATCC27853) strains, and Candida albicans yeast were supplied from Mardin Artuklu University Microbiology Laboratory. Cancerous (ovarian sarcoma (Skov-3); human colorectal adenocarcinoma (Caco-2); glioblastoma (U118)) and healthy (human dermal fibroblast (HDF)) cell lines were supplied from Dicle University Central Research Cell Laboratory.

\subsection{Method}

2.2.1. Preparing the Plant Extract of Gundelia tournefortii. The green leaves of GT, which were collected beforehand for the experimental study, were flushed and dried. 10 grams of dried green leaves and $100 \mathrm{~mL}$ of distilled water were left to boil. Afterwards, it was filtered and the obtained extract was left to cool at room conditions.

2.2.2. Biosynthesis of the Gold Nanoparticles (AuNPs). For synthesizing of AuNPs, $3 \mathrm{mM}$ aqueous Au solution was prepared from the commercially purchased solid form of tetrachloroauric acid $\left(\mathrm{HAuCl}_{4} \cdot 3 \mathrm{H}_{2} \mathrm{O}\right) .50 \mathrm{~mL}$ of GT leaf extract and $75 \mathrm{~mL}$ of $3 \mathrm{mM} \mathrm{HAuCl}_{4} \cdot 3 \mathrm{H}_{2} \mathrm{O}$ were left to react in a flask at $45^{\circ} \mathrm{C}$. The color change was seen after one hour, and the reaction was complete. Then, the solution (dark black colored) was centrifuged (10000 rpm), and the solid part was separated. The separated solid part was washed several times. 


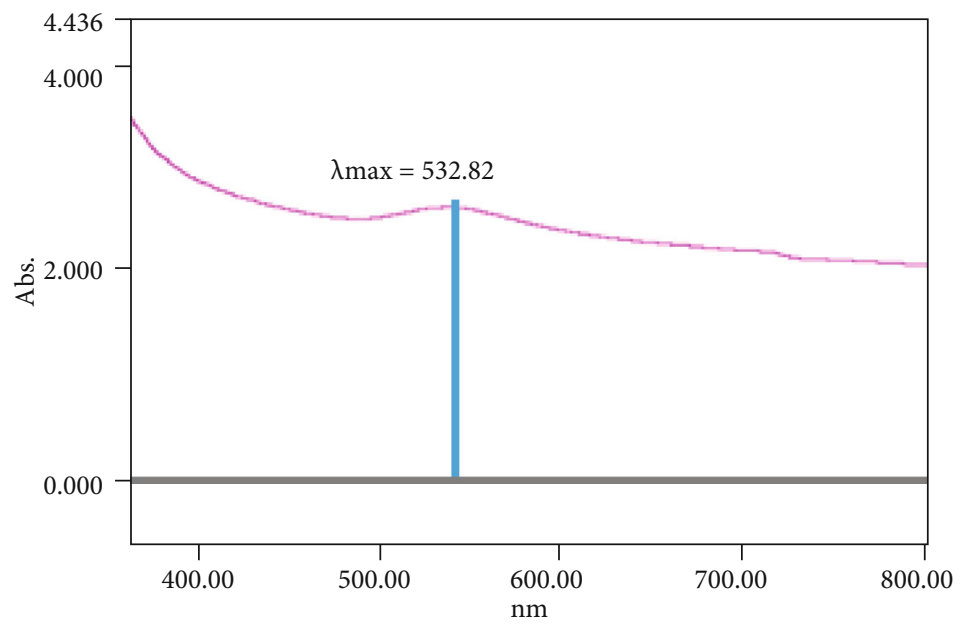

FIGURE 1: Maximum absorbance value with UV-vis spectrophotometer as a result of interaction of Gundelia tournefortii plant extract and $\mathrm{HAuCl}_{4} \cdot 3 \mathrm{H}_{2} \mathrm{O}$ solution.

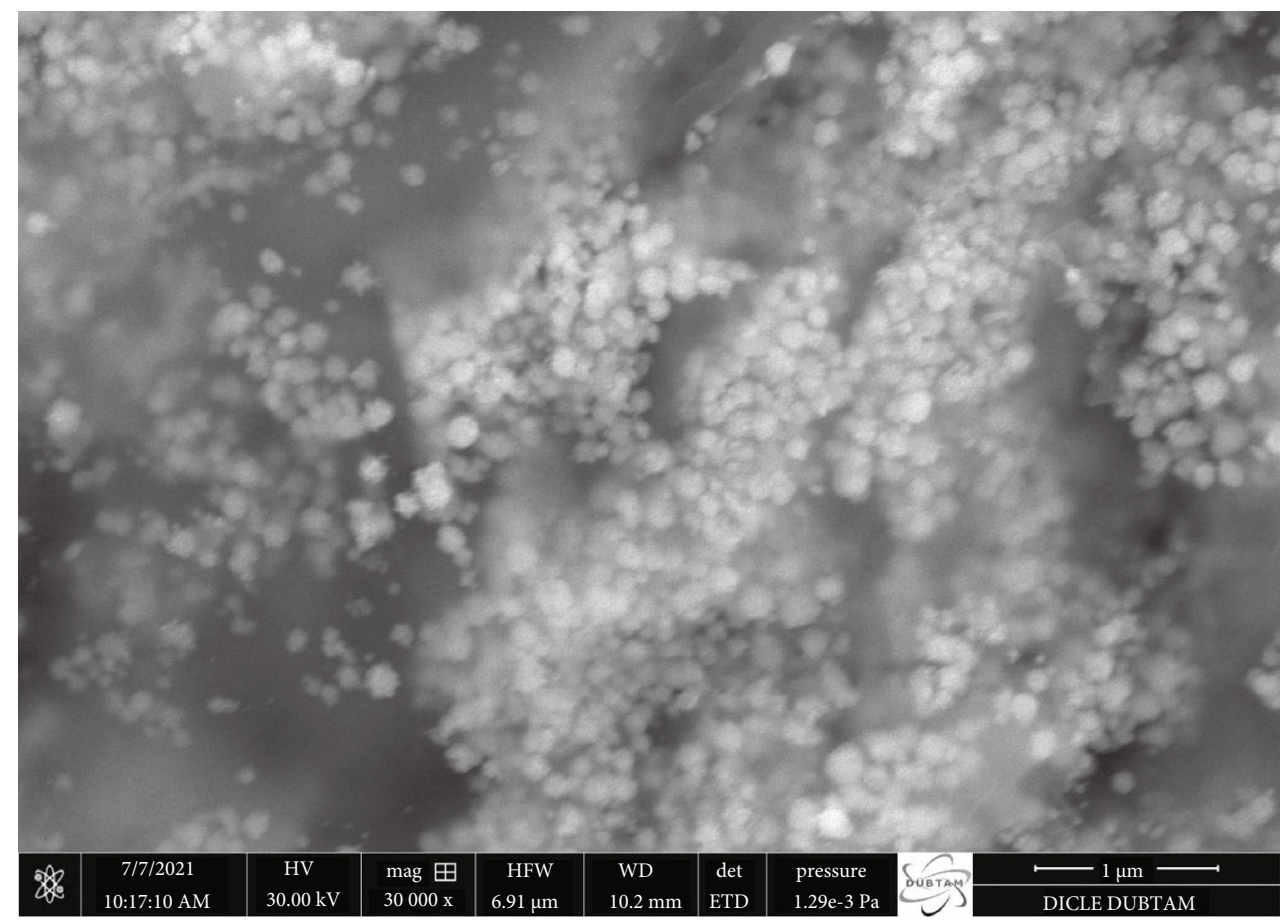

FIGURE 2: FE-SEM image of AuNPs obtained from Gundelia tournefortii plant extract at $1 \mu \mathrm{m}$.

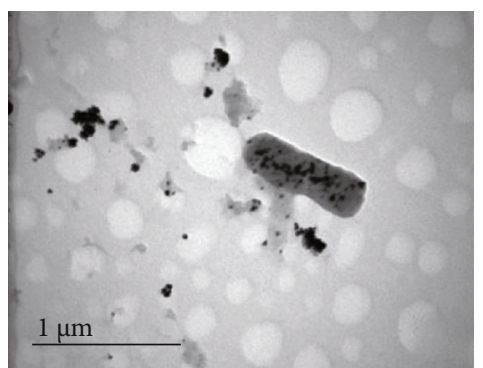

(a)

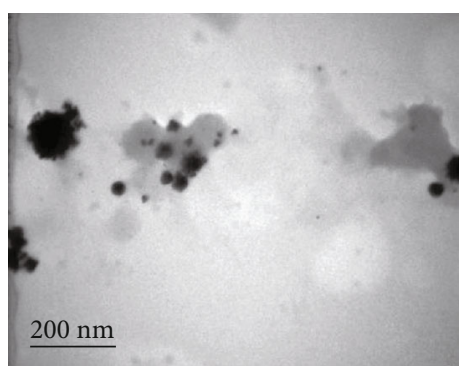

(b)

FIgUre 3: TEM image of AuNPs obtained from Gundelia tournefortii plant extract at $1 \mu \mathrm{m}$ (a) and $200 \mathrm{~nm}$ (b). 


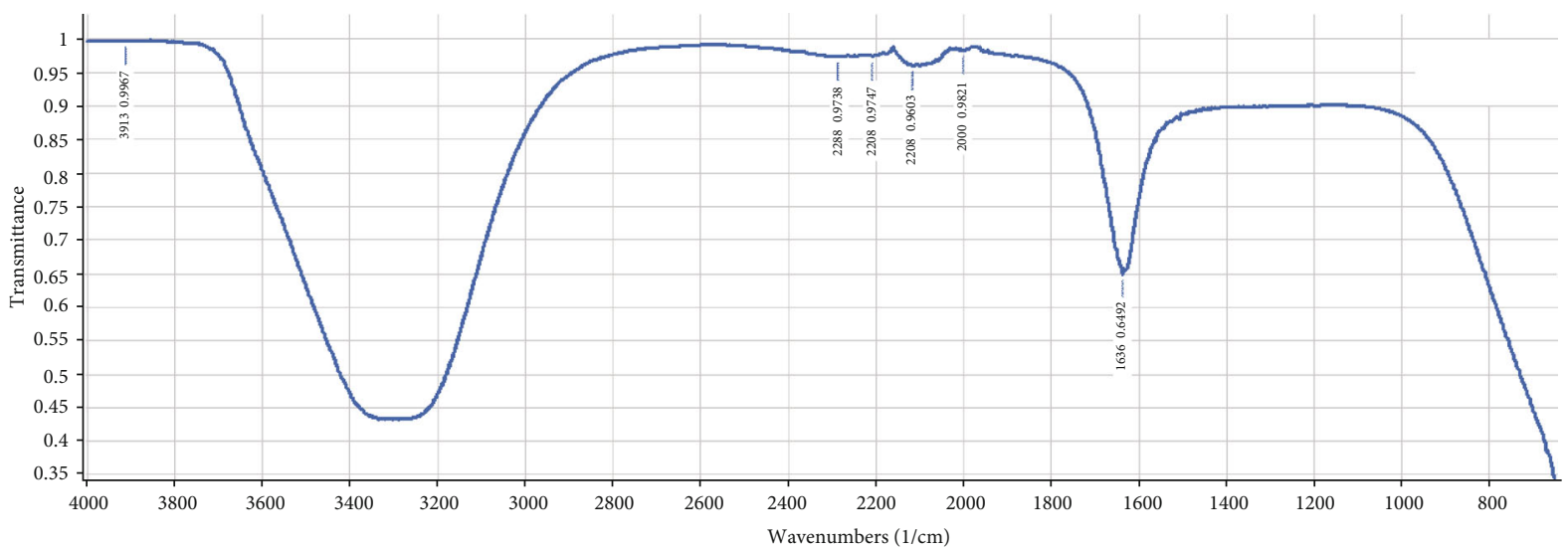

(a)

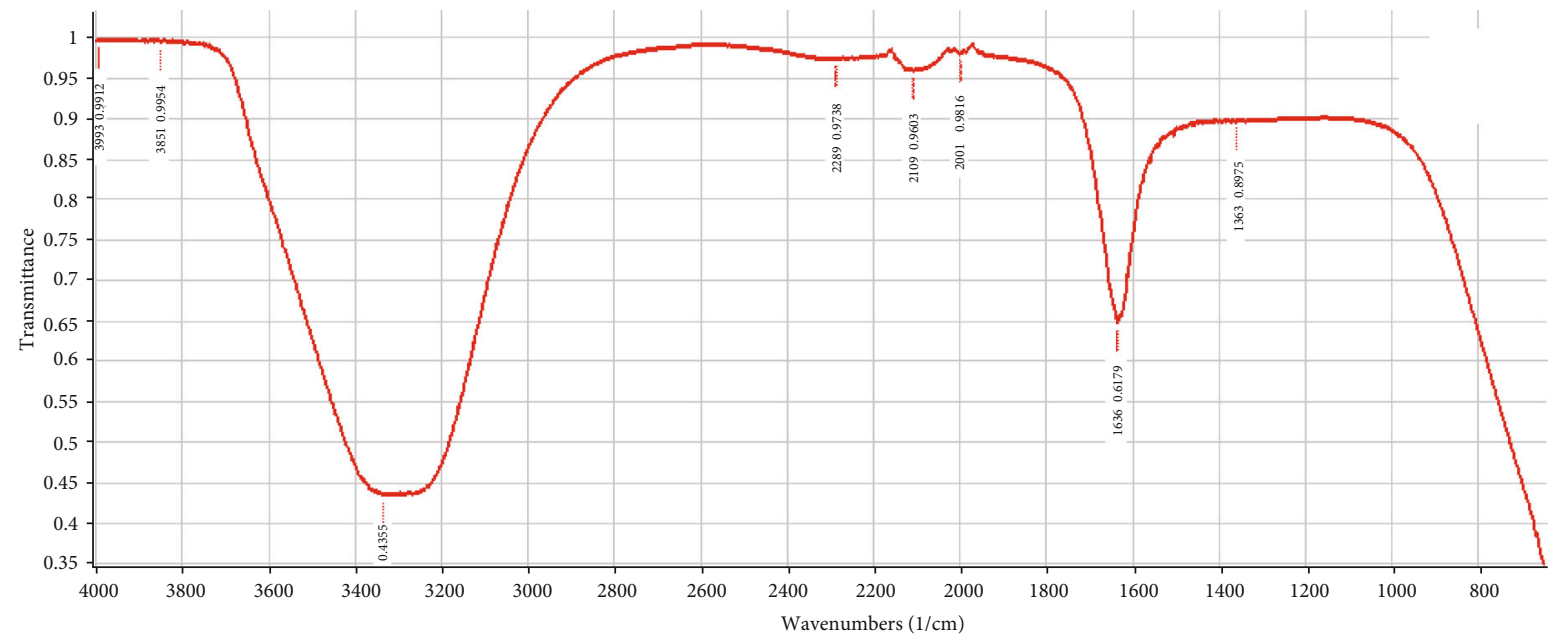

(b)

FIGURE 4: (a) FT-IR spectroscopy diagram of Gundelia tournefortii plant extract; (b) FT-IR spectroscopy diagram of the liquid taken after color change (GT-AuNPs).

The residue was left in the oven at $55^{\circ} \mathrm{C}$ for 48 hours to dry completely. The dried part was ground for further use.

2.2.3. Determination of Characteristic Properties of Biologically Synthesized AuNPs. A UV-vis spectrophotometer (Agilent CARY 60) detected the presence of the AuNPs by scanning the reaction mixture $(300-800 \mathrm{~nm})$. Shape, nanosize, crystalline structure, and surface plasmon distribution of AuNPs were characterized by FE-SEM-TEM (Quanta), EDX (Quanta FEG 250), XRD (Ultima IV, Rigaku, CBO), and Zetasizer (Malvern Panalytical). The average crystalline size of the gold nanoparticles was calculated by the following formula: $D=K \lambda /(\beta \cos \theta)[28,29]$. FT-IR (P.E. Spect. 100) was used to determine the functional groups.

\subsubsection{Antimicrobial Activities of AuNPs on Pathogen} Microorganisms. The antimicrobial activities of the synthesized nanoparticles on the gram (-) and gram (+) bacteria strains and yeast were determined by the microdilution method. The lowest concentration at which growth was observed after incubation was determined as the MIC value
$[30,31]$. Also, commercial antibiotics fluconazole, vancomycin, and colistin and $1 \mathrm{mM} \mathrm{HAuCl} \mathrm{H}_{4} \cdot 3 \mathrm{H}_{2} \mathrm{O}$ solution were used to compare the antimicrobial effects of plant-based synthesized gold nanoparticles on pathogen microorganisms.

2.2.5. Evaluation of Cytotoxic Activities of AuNPs on Cancerous and Healthy Cell Lines by the MTT Method. RPMI 1640 medium was used in culture medium to generate Skov-3 cells, and DMEM was used for other cell types. Conditions for cell cultures were determined according to the literature [32]. Cell lines grown in culture medium were exposed to AuNPs for 48 hours in the concentration range of $25-200 \mu \mathrm{g} / \mathrm{mL}$. At the end of the incubation period, MTT solution was added to the microplate wells and incubated for 3 hours. Finally, DMSO was added to the culture medium and kept at $25 \pm 2$ ${ }^{\circ} \mathrm{C}$ for $15 \mathrm{~min}$. The absorbance of the microplates is measured spectrophotometrically (MultiScan Go, Thermo) at $540 \mathrm{~nm}$. The $\%$ viability was calculated using the formula below [32].

$$
\text { \%viability }=\frac{U}{C} * 100 \text {, }
$$




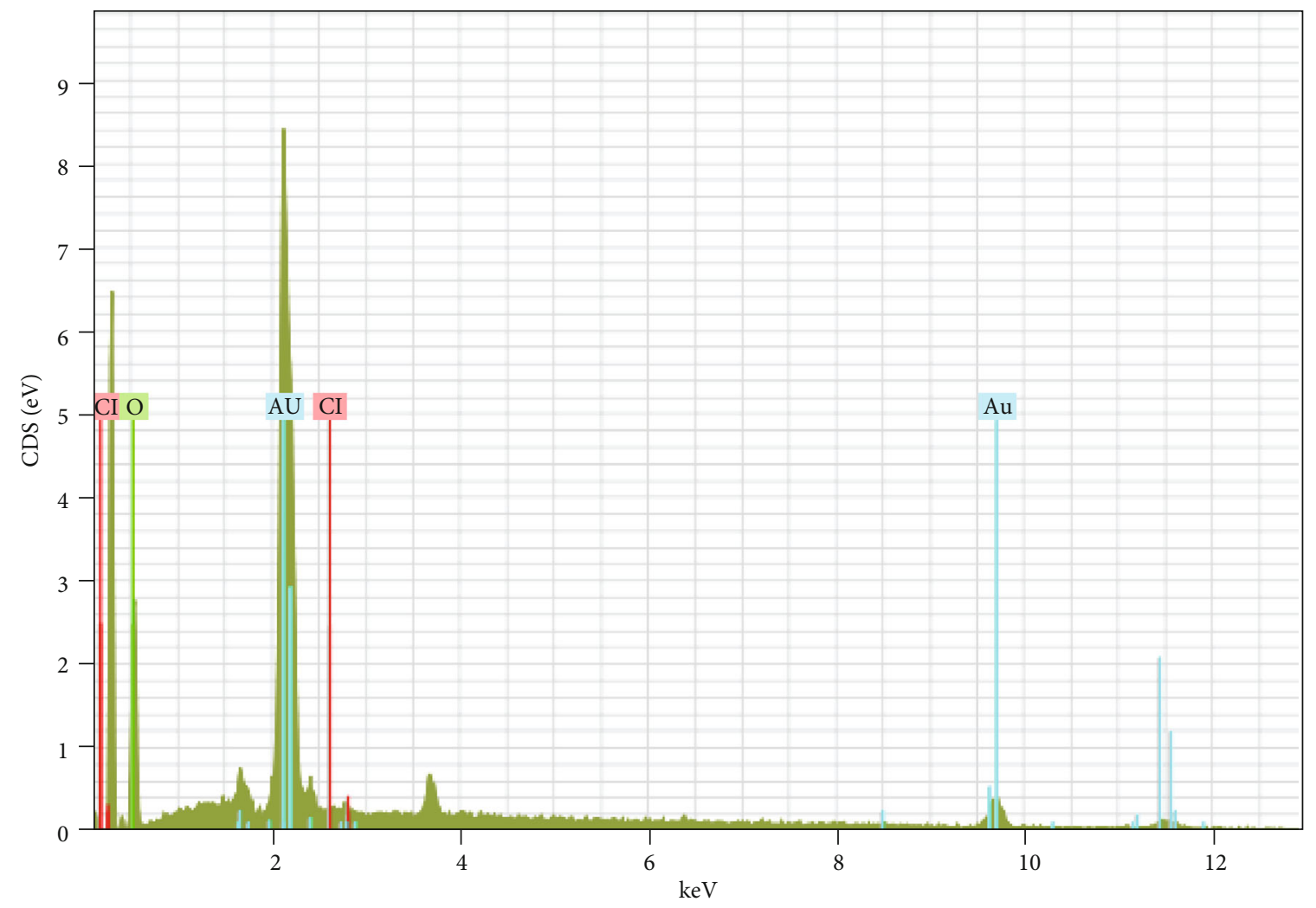

FIGURE 5: Image of elemental composition as a result of EDX analysis of the presence of AuNPs obtained from Gundelia tournefortii plant extract.

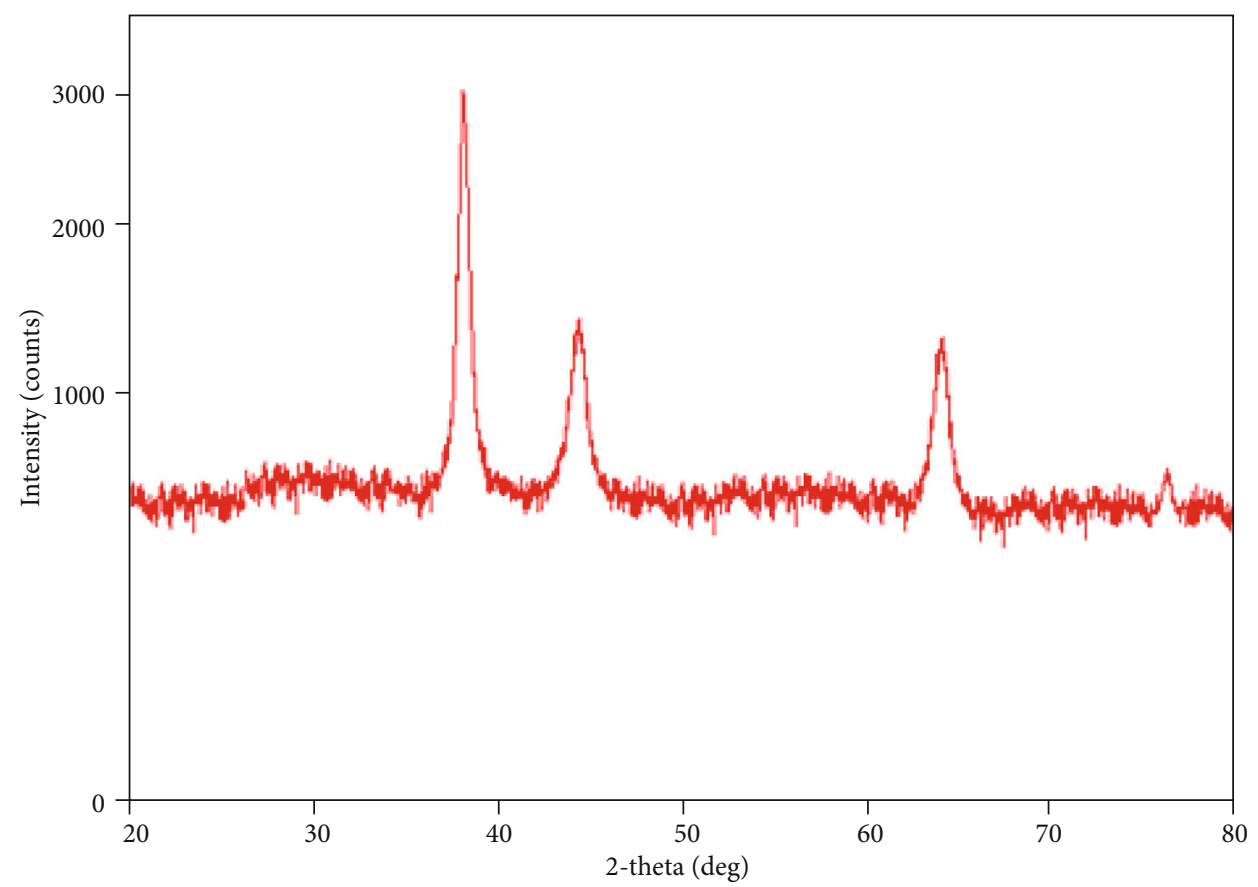

FIgURE 6: X-ray diffraction diagram of the crystal morphology of biocompatible synthesis GT-AuNPs. 


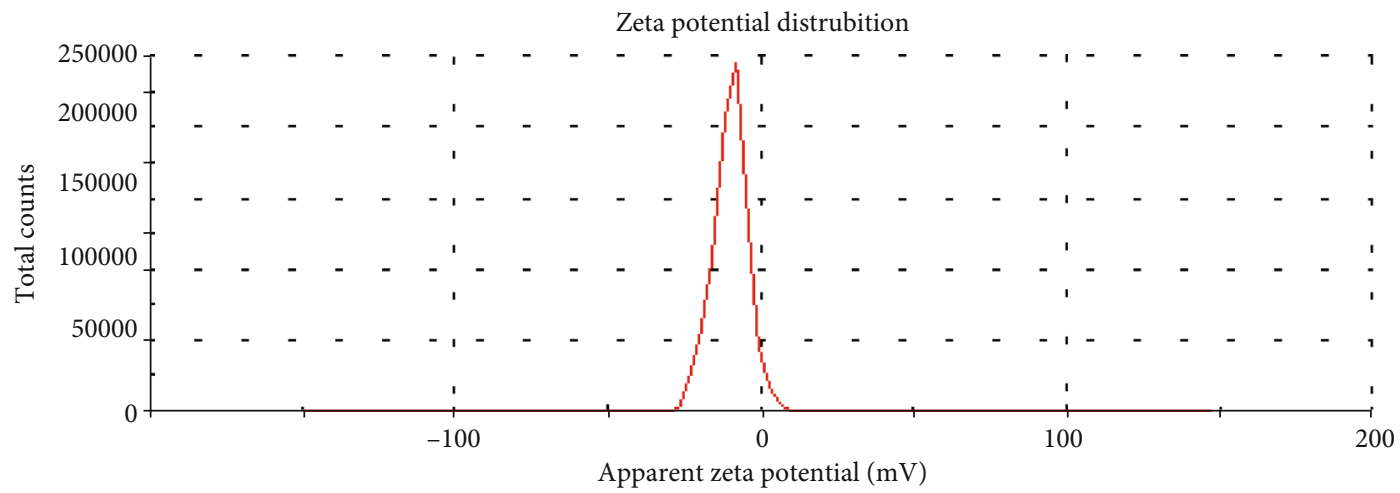

Figure 7: Zeta potential distribution of biocompatible synthesis GT-AuNPs.

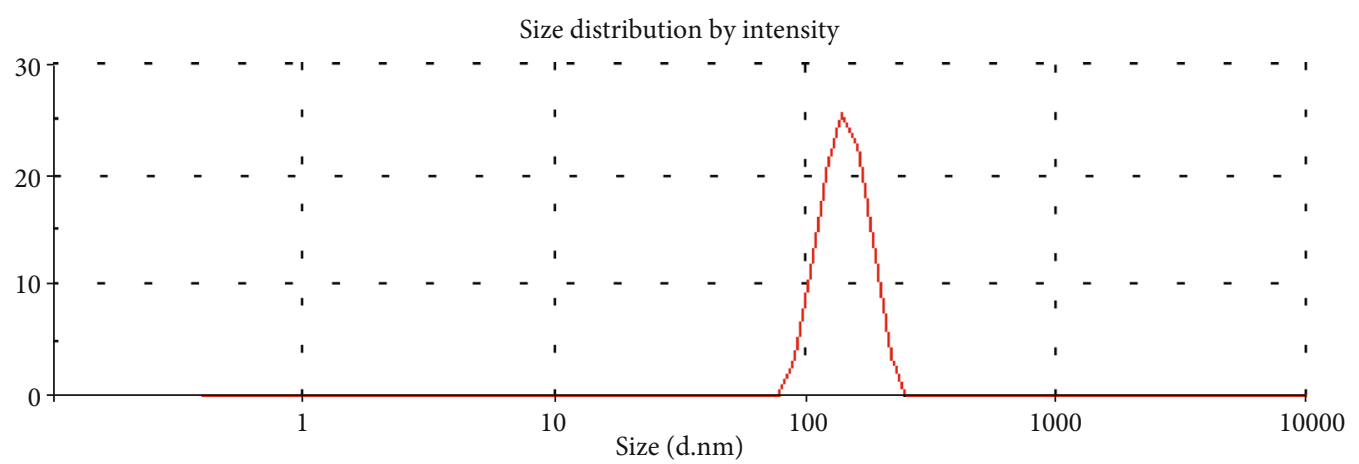

FIGURE 8: Zetasizer distribution of biocompatible synthesis GT-AuNPs.

where $U$ is the absorbance of cell lines treated with AuNPs and $C$ is the absorbance of control cells.

\section{Results}

3.1. Spectroscopic Analysis Data. One hour after the GT green leaves and $1 \mathrm{mM}$ gold solution used in the study were left in the mixture, the formation of AuNPs is seen in Figure 1, with a distinct peak at $532.82 \mathrm{~nm}$ due to the color change in the UV-vis spectrum.

3.2. FE-SEM and TEM Data of Plant-Based AuNPS. Shape and nanosize distribution of plant-based synthesized AuNPs were investigated in detail using FE-SEM and TEM images (Figures 2 and 3).

3.3. FTIR. FTIR data were used to identify functional groups possessed by biologically synthesized GT-AuNPs in the 600$4000 \mathrm{~cm}^{-1}$ spectrum range before and after synthesis (Figures 4(a) and 4(b)). Figure 4(b) shows the bands observed on the FTIR spectrum of GT-AuNPs at 3993, $3851,3350,2289,2109,2001,1636$, and $1363 \mathrm{~cm}^{-1}$.

3.4. Formation Data of Gold Nanoparticles (EDX Diagram). The elemental combination of plant-based synthesized AuNPs was determined by EDX diagrams. The absorption of MNPs (gold) crystallised was characterized by strong EDX signals at 2.2 and $9.4 \mathrm{keV}$ (Figure 5).

3.5. XRD Analysis Data of GT-AuNPs. The X-ray diffraction pattern of the synthesized GT-AuNPs is shown in Figure 6.
The average size of the GT-AuNP nanoparticles was calculated as $23.53 \mathrm{~nm}$ [29].

3.6. Zeta Potential (ZP) and Size Distribution by Intensity. The ZP distribution of the GT-AuNPs was found as -9.96 $\mathrm{mV}$ (Figure 7). Also, the size distribution of the synthesized AuNPs was found as 146.0 nanometers in the measurements made with Zetasizer (Figure 8).

3.7. Evaluation of Antimicrobial Activities of AuNPs. The inhibitory effects of synthesized gold nanoparticles on the growth of pathogenic microorganisms (gram (+, -); yeast) were compared using standard antibiotics (vancomycin, colistin, and fluconazole: $128 \mathrm{mg} / \mathrm{mL}$ ) (Table 1).

3.8. Cytotoxic Activities of AuNPs on Cancerous Cell Lines. AuNPs obtained by biosynthesis of GT leaf extract was applied to the healthy cell (Human Dermal Fibroblasts/ HDF), and three different cancerous cell lines (Skov-3, $\mathrm{CaCo}-2$, and U118) and their anticancer effects were determined by the MTT method. Figure 9 shows the data obtained as a result of this application.

\section{Discussion}

Colloidal solutions of AuNPs show intense color due to SPR caused by bulk oscillation of free conduction electron [30]. For this reason, UV-vis spectroscopy should be used to reveal the formation and stability of AuNPs in an aqueous solution by color change [31]. Recent studies have reported that the absorption SPR peak value of metal nanoparticles 

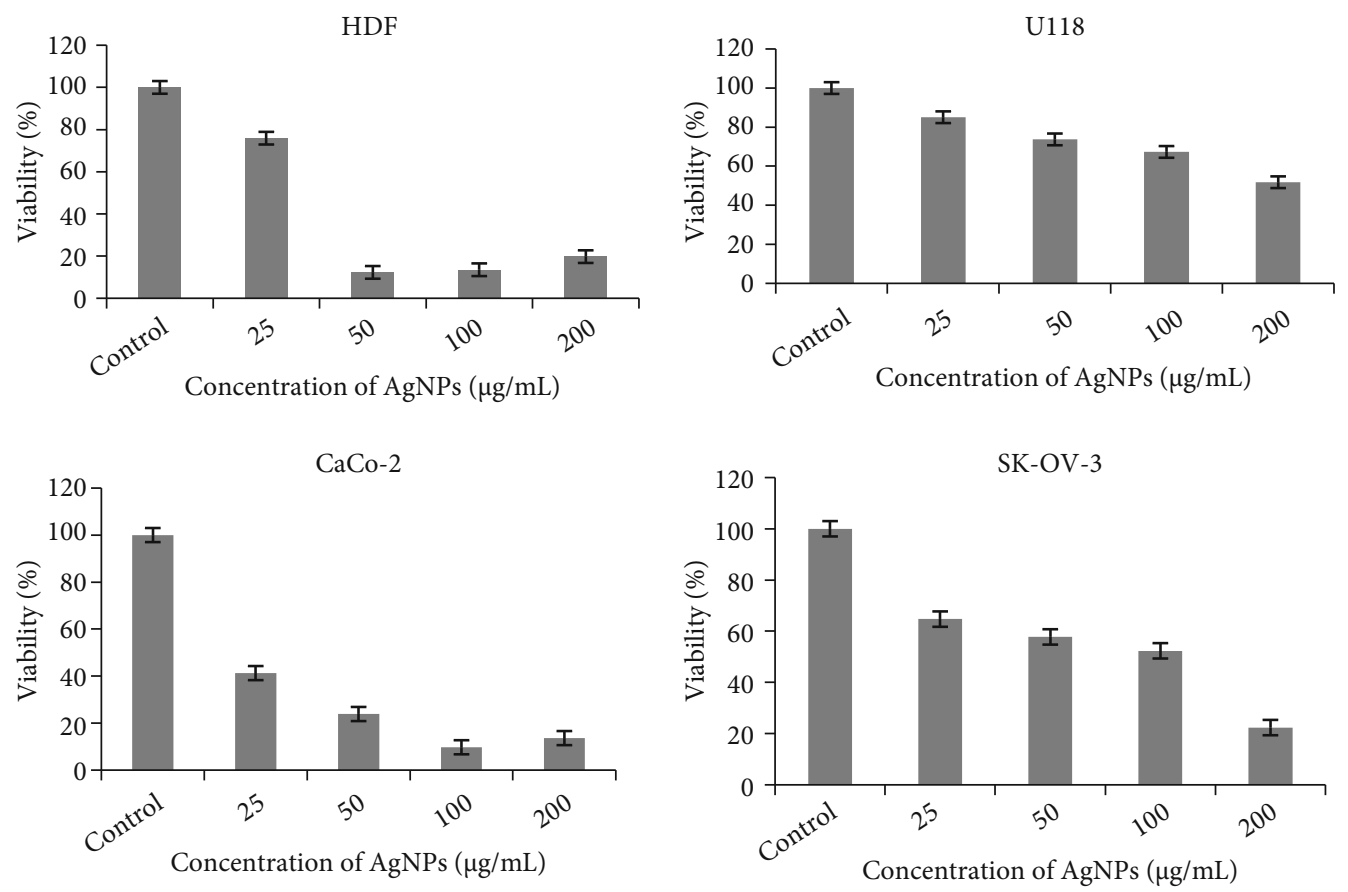

FIGURE 9: Evaluation of the percent viability rates as a result of the cytotoxic effect of AuNPs two days after combining with cell lines.

TABLE 1: The minimum inhibition concentrations values of GTAuNPs, $\mathrm{AuCI}_{4} \cdot 3 \mathrm{H}_{2} \mathrm{O}$, and standard antimicrobial agents $(\mathrm{mg} / \mathrm{mL})$.

\begin{tabular}{lccc}
\hline $\begin{array}{l}\text { Pathogen } \\
\text { microorganisms }\end{array}$ & $\begin{array}{c}\mathrm{GT}- \\
\mathrm{AuNPs}\end{array}$ & $\mathrm{AuCI}_{4} \cdot 3 \mathrm{H}_{2} \mathrm{O}$ & $\begin{array}{c}\text { Standard } \\
\text { antibiotics* }\end{array}$ \\
\hline $\begin{array}{l}\text { S. aureus ATCC } \\
29213\end{array}$ & 0.25 & 0.25 & 2 \\
$\begin{array}{l}\text { B. subtilis } \\
\text { ATCC11774 }\end{array}$ & 0.125 & 0.5 & 1 \\
$\begin{array}{l}\text { E. coli ATCC25922 } \\
\text { P. aeruginosa }\end{array}$ & 1.0 & 1.0 & 2 \\
ATCC27853 & 0.5 & 5.0 & 1 \\
C. albicans & 0.5 & 0.125 & 2 \\
\hline
\end{tabular}

* S. aureus, B. subtilis (vancomycin $128 \mathrm{mg} / \mathrm{mL}$ ); E. coli, P. aeruginosa (colistin $128 \mathrm{mg} / \mathrm{mL}$ ); C. albicans (fluconazole $128 \mathrm{mg} / \mathrm{mL}$ ).

can be measured in the wavelength range of $200-800 \mathrm{~nm}$ in metallic nanoparticles [32]. It has also been reported that the SPR value in AuNPs is typically in the wavelength range of 500-550 $\mathrm{nm}$. The maximum absorbance value determined at $532.82 \mathrm{~nm}$ in our study is compatible with the reference values and shows the stability of the synthesized gold nanoparticles [19, 30, 32-35].

FESEM and TEM analyzes data were used to determine the dimensions of the nanoparticles. Analysis data show that biologically synthesized gold nanoparticles coexist in stable small groups owing to their functional groups and surface charges [31]. These data confirm that AuNPs obtained by plant-based synthesis are stable and nanosized. The FESEM and the TEM images show that the gold particles are predominantly spherical and hexagonal shaped (Figure 3). Many researchers have also reported spherical-shaped AuNPs in their studies [35-37]. Nanoparticles with these shapes can easily pass through the cell membrane. Therefore, it can damage target cell organelles and enzymatic systems and the damaged cells are forced into apoptosis [35].

In order to determine the presence of specific functional groups responsible for the reduction reactions of gold nanoparticles from gold salt using biological material, the FTIR measurements obtained before (Figure 4(a)) and after synthesis (Figure 4(b)) were compared and evaluated. Examining the biomolecules involved in reduction during the formation of AuNPs (Figures 4(a) and 4(b)), the absorption peak at $1636 \mathrm{~cm}^{-1}$ may be due to the reduction in carbonyl $(\mathrm{C}=\mathrm{O})$ stretch vibrations. It can be said that the absorption peak at $3350 \mathrm{~cm}^{-1}$ belongs to the $-\mathrm{OH}$ and $-\mathrm{NH}$ stretches, and the absorption peak at $2109 \mathrm{~cm}^{-1}$ belongs to the $-\mathrm{C}=\mathrm{C}$ groups. Probably, these specific groups are liable for the degradation of gold ions [38]. EDX data clearly reveals that the biosynthesized metallic nanosized crystals contain gold in their content and have an elemental structure. Moreover, other prominent nonmetal peaks $(\mathrm{C}, \mathrm{Cl}$, and $\mathrm{O})$ seen in the EDX profile can be speculated to be due to the structural content of the GT plant [38].

$\mathrm{ZP}$ analysis measures the surface charge of the synthesized metallic nanoparticle. A negative measurement of the $\mathrm{ZP}$ value indicates that it has the potential to bind with molecules. This is another indication that AuNP has a stable structure. The average $\mathrm{ZP}$ values of AuNPs synthesized from different plants were reported to be between $-12 \mathrm{mV}$ and $-37 \mathrm{mV}$. On the other hand, nanoparticles with a significantly lower negative charge can more easily enter the cell and interact with cellular structures [39-44]. This creates an important advantage for studies with pathogenic microorganisms and cancerous cells. The strong antimicrobial 
and anticancer activity of synthesized gold nanoparticles is highly dependent on their surface charge [35].

It is known that pathogenic microorganisms develop various resistance mechanisms against traditionally used antibiotics over time. This situation encourages researchers to find alternative ways. One of the reasons why researchers have recently increased interest in nanoparticles is that they can be used as potential antimicrobial agents $[34,45]$. The antimicrobial mechanism of AuNPs is due to the fact that they have functional groups, especially thiol, that cause cell death by causing damage to the bacterial cell membrane, bacterial cell wall, ribosome, and mitochondria [1]. Although AuNPs significantly suppress the proliferation of bacteria [44], it was reported that they are generally more resistant to some fungal species than bacteria [45]. The results obtained in the study confirm the findings of previous studies. It was determined that the synthesized GT-AuNPs were $8,8,4,2$, and 2 times more effective on the growth of $S$. aureus, B. subtilis, C. albicans, E. coli, and P. aeruginosa compared to the antibiotics used as a standard, respectively.

The effect of several concentrations $(25,50,100$, and $200 \mu \mathrm{g} \mathrm{m}^{-1}$ ) of GT-AuNPs on the U118, CaCO-2, SKOV-3, and HDF cell line has been examined using an in vitro MTT assay. The obtained results show that the biosynthesized AuNPs have been prominent cytotoxic activity against the cancerous cell lines. When the data are analyzed after 48 hours, it is seen that there is no toxic effect in HDF with a survival rate of $76 \%$ at $25 \mu \mathrm{g} / \mathrm{mL}$ concentration. It was observed that $25 \mu \mathrm{g} / \mathrm{mL}$ concentration suppressed viability by $14-59 \%$ in cancer cell lines. Despite the increase in the concentration of AuNPs in cancerous cells, the enhancement in the percentage of viability is due to the proliferative properties of AuNPs for these cells [46].

It is known that NPs show strong oxidative properties [47]. NPs tend to settle in biomolecules such as cell membranes and nuclei. After localization, they exert a toxic effect by stimulating apoptosis with an increase in ROS [46]. Exposure time, charge, degree of accumulation, concentration, the chemistry of surface composition, shape, and size be an able significant effect on the toxicity of AuNPs [48]. It was reported that the concentrations above $3.75 \mu \mathrm{g} / \mathrm{mL}$ and $5 \mu \mathrm{g} / \mathrm{mL}$ of NPs showed toxic effects on Caco-2 cells [49]. In other studies, suppressor concentrations in Skov-3 cells were reported as $9.4 \mu \mathrm{g} / \mathrm{mL}$ [50] and $29.36 \mu \mathrm{g} / \mathrm{mL}$ [51].

\section{Conclusion}

Most of the spherical nanoparticle and stable structure gold colloids were synthesized using an aqueous GT leaf extract. This preferred method is environmentally friendly, simple, economical, and efficient. UV-vis absorption, XRD, and EDX analysis confirmed the synthesis of AuNPs. TEM and FE-SEM structure analyzes revealed that AuNPs were predominantly spherical with an average size of approximately $23.53 \mathrm{~nm}$. It was observed that the obtained nanoparticles showed strong antibacterial and anticandidal effects even at low concentrations.

The cytotoxic effects of GT-AuNPs in their use were evaluated by the MTT method. For healthy cell HDF,
$25 \mu \mathrm{g} / \mathrm{mL}$ concentrations did not show any toxic effect. In cancer cell lines, $25 \mu \mathrm{g} / \mathrm{mL}$ concentrations of GT-AuNPs suppressed viability by $14-59 \%$. The cytotoxic effect was studied for the first time with this application to the U118 glioblastoma cancer cell line. Different applications can be made on the parameters that determine the properties of GT-AuNPs, contributing to medical applications for the search for antimicrobial and anticancer agents. The most important advantage in the biological synthesis of gold nanoparticles is the rich secondary metabolite content of plants. This provides that the surface of the gold particles obtained in nanosize is covered by a negative charge. Charged nanoparticles can bond more easily with biomolecules in cells. Because of these properties, they can be used as novel anticancer and antimicrobial materials.

\section{Data Availability}

All data used to support the findings of this study are included within the article.

\section{Conflicts of Interest}

The authors declare that there are no conflicts of interest regarding the publication of this paper.

\section{Acknowledgments}

The authors are thankful to Mardin Artuklu University for providing all necessary research facilities to carry out this research.

\section{References}

[1] V. Sunderam, D. Thiyagarajan, A. V. Lawrence, S. S. S. Mohammed, and A. Selvaraj, "_In-vitro_ antimicrobial and anticancer properties of green synthesized gold nanoparticles using _Anacardium occidentale_ leaves extract," Saudi Journal of Biological Sciences, vol. 26, no. 3, pp. 455-459, 2019.

[2] P. Clarance, B. Luvankar, J. Sales et al., "Green synthesis and characterization of gold nanoparticles using endophytic fungi _Fusarium solani_and its in-vitro anticancer and biomedical applications," Saudi Journal of Biological Sciences, vol. 27, no. 2, pp. 706-712, 2020.

[3] M. Hosny, M. Fawzy, A. M. Abdulfetah, E. E. Fawzy, and A. S. Eltaweil, "Comparative study on the potentialities of two halophytic species in the green synthesis of gold nanoparticles and their anticancer, antioxidant and catalytic efficiencies," Advanced Powder Technology, vol. 32, no. 9, pp. 3220-3233, 2021.

[4] M. Bandeira, M. Giovanela, M. Roesch-Ely, D. M. Devine, and C. J. da Silva, "Green synthesis of zinc oxide nanoparticles: a review of the synthesis methodology and mechanism of formation," Sustainable Chemistry and Pharmacy, vol. 15, article 100223, 2020.

[5] U. M. Badeggi, E. Ismail, A. O. Adeloye et al., "Green synthesis of gold nanoparticles capped with procyanidins from Leucosidea sericea as potential antidiabetic and antioxidant agents," Biomolecules, vol. 10, no. 3, p. 452, 2020. 
[6] C. Chellamuthu, R. Balakrishnan, P. Patel, R. Shanmuganathan, A. Pugazhendhi, and K. Ponnuchamy, "Gold nanoparticles using red seaweed Gracilaria verrucosa: green synthesis, characterization and biocompatibility studies," Process Biochemistry, vol. 80, pp. 58-63, 2019.

[7] N. Aktepe and A. Baran, "Fast and low-cost biosynthesis of AgNPs with almond leaves: medical applications with biocompatible structures," Progress in Nutrition, vol. 23, no. 3, article e2021271, 2021.

[8] F. T. Thema, E. Manikandan, M. S. Dhlamini, and M. Maaza, "Green synthesis of $\mathrm{ZnO}$ nanoparticles via_Agathosma betulina_ natural extract," Matererial Letter, vol. 161, pp. 124127, 2015.

[9] M. Soliman, S. H. Qari, A. Abu-Elsaoud, M. El-Esawi, H. Alhaithloul, and A. Elkelish, "Rapid green synthesis of silver nanoparticles from blue gum augment growth and performance of maize, fenugreek, and onion by modulating plants cellular antioxidant machinery and genes expression," Acta Physiologiae Plantarum, vol. 42, no. 9, pp. 1-16, 2020.

[10] S. S. Salem, E. F. El-Belely, G. Niedbała et al., "Bactericidal and in-vitro cytotoxic efficacy of silver nanoparticles (Ag-NPs) fabricated by endophytic actinomycetes and their use as coating for the textile fabrics," Nanomaterials, vol. 10, no. 10, p. 2082, 2020.

[11] C. J. Pandian, R. Palanivel, and S. Dhananasekaran, "Green synthesis of nickel nanoparticles using _Ocimum sanctum_ and their application in dye and pollutant adsorption," Chinese Journal of Chemical Engineering, vol. 23, no. 8, pp. 1307-1315, 2015.

[12] C. P. Devatha, A. K. Thalla, and S. Y. Katte, "Green synthesis of iron nanoparticles using different leaf extracts for treatment of domestic waste water," Journal of Cleaner Production, vol. 139, pp. 1425-1435, 2016.

[13] A. Thirumurugan, P. Aswitha, C. Kiruthika, S. Nagarajan, and A. N. Christy, "Green synthesis of platinum nanoparticles using _Azadirachta indica_ - an eco- friendly approach," Matererial Letter, vol. 170, pp. 175-178, 2016.

[14] V. Cittrarasu, D. Kaliannan, K. Dharman et al., "Green synthesis of selenium nanoparticles mediated from _Ceropegia bulbosa_ Roxb extract and its cytotoxicity, antimicrobial, mosquitocidal and photocatalytic activities," Scientific Reports, vol. 11, no. 1, p. 1032, 2021.

[15] L. Maryam, S. S. Usmani, and G. P. Raghava, "Computational resources in the management of antibiotic resistance: speeding up drug discovery," Drug Discovery Today, vol. 26, no. 9, pp. 2138-2151, 2021.

[16] H. Chandra, P. Kumari, E. Bontempi, and S. Yadav, "Medicinal plants: treasure trove for green synthesis of metallic nanoparticles and their biomedical applications," Biocatalysis and Agricultural Biotechnology, vol. 24, article 101518, 2020.

[17] G. N. Maity, P. Maity, I. Choudhuri et al., "Green synthesis, characterization, the antimicrobial and cytotoxic effect of silver nanoparticles using arabinoxylan isolated from Kalmegh," International Journal of Biological Macromolecules, vol. 1, no. 162, pp. 1025-1034, 2020.

[18] A. Singh, P. K. Gautam, A. Verma et al., "Green synthesis of metallic nanoparticles as effective alternatives to treat antibiotics resistant bacterial infections: a review," Biotechnology Reports, vol. 25, no. 2020, article e00427, 2020.

[19] A. Rónavári, N. Igaz, D. I. Adamecz et al., "Green silver and gold nanoparticles: biological synthesis approaches and poten- tials for biomedical applications," Molecules, vol. 26, no. 4, p. 844, 2021.

[20] F. Behzad, S. M. Naghib, M. A. J. Kouhbanani, S. N. Tabatabaei, Y. Zare, and K. Y. Rhee, "An overview of the plantmediated green synthesis of noble metal nanoparticles for antibacterial applications," Journal of Industrial and Engineering Chemistry, vol. 94, pp. 92-104, 2021.

[21] S. M. Mousavi, S. A. Hashemi, Y. Ghasemi et al., "Green synthesis of silver nanoparticles toward bio and medical applications: review study," Artificial Cells, Nanomedicine, and Biotechnology, vol. 46, no. sup3, pp. S855-S872, 2018.

[22] P. Kumari, M. Alam, and W. A. Siddiqi, "Usage of nanoparticles as adsorbents for waste water treatment: an emerging trend," Sustainable Materials and Technologies, vol. 22, article e00128, 2019.

[23] S. A. Akintelu and A. S. Folorunso, "A review on green synthesis of zinc oxide nanoparticles using plant extracts and its biomedical applications," BioNanoScience, vol. 10, no. 4, pp. 848863,2020 .

[24] E. Kowsalya, K. Mosachristas, P. Balashanmugam, V. Manivasagan, T. Devasena, and C. R. I. Jaquline, "Sustainable use of biowaste for synthesis of silver nanoparticles and its incorporation into gelatin-based nanocomposite films for antimicrobial food packaging applications," Journal of Food Process Engineering, vol. 44, no. 3, article e13641, 2021.

[25] C. Keskin, "Medicinal plants and their traditional uses," Journal of Advence in Plant Biology, vol. 1, no. 2, pp. 8-12, 2018.

[26] D. Dastan and M. Yousefzadi, "Volatile oil constituent and biological activity of Gundelia tournefortii L. from Iran," Journal of Reports in Pharmaceutical Sciences, vol. 5, no. 1, pp. 18 24, 2016.

[27] S. Abu-Lafi, B. Rayan, S. Kadan, M. Abu-Lafi, and A. Rayan, "Anticancer activity and phytochemical composition of wild $<\mathrm{i}>$ Gundelia tournefortii</i>," Oncology Letters, vol. 17, no. 1, pp. 713-717, 2019.

[28] T. V. Surendra and S. M. Roopan, "Photocatalytic and antibacterial properties of phytosynthesized $\mathrm{CeO}_{2}$ NPs using _Moringa oleifera_ peel extract," Journal of Photochemistry and Photobiology B: Biology, vol. 161, pp. 122-128, 2016.

[29] N. Aktepe and A. Baran, "Biosynthesis of AgNPs by the extract from waste leaves of Citrullus lanatus sp. (watermelon): characterization, antibacterial and antifungal effects," Progress in Nutrition, vol. 23, no. 3, article e2021243, 2021.

[30] D. Wang, S. C. Pillai, S. H. Ho, J. Zeng, Y. Li, and D. D. Dionysiou, "Plasmonic-based nanomaterials for environmental remediation," Applied Catalysis B: Environmental, vol. 237, pp. 721-741, 2018.

[31] A. Baran, M. F. Baran, C. Keskin et al., "Ecofriendly/rapid synthesis of silver nanoparticles using extract of waste parts of artichoke (Cynara scolymus L.) and evaluation of their cytotoxic and antibacterial activities," Journal of Nanomaterials, vol. 2021, 10 pages, 2021.

[32] M. Elshikh, S. Ahmed, S. Funston et al., "Resazurin-based 96well plate microdilution method for the determination of minimum inhibitory concentration of biosurfactants," Biotechnology Letters, vol. 38, no. 6, pp. 1015-1019, 2016.

[33] P. V. Kumar, S. M. J. Kala, and K. S. Prakash, "Green synthesis of gold nanoparticles using _Croton Caudatus Geisel_ leaf extract and their biological studies," Materials Letter, vol. 236, no. 1, pp. 19-22, 2019. 
[34] A. Hatipoğlu, "Green synthesis of gold nanoparticles from Prunus cerasifera pissardii nigra leaf and their antimicrobial activities on some food pathogens," Progress in Nutrition, vol. 23, no. 3, article e2021241, 2021.

[35] C. Keskin, M. F. Baran, M. N. Atalar, and A. Baran, "Environmentally friendly rapid synthesis of gold nanoparticles from Artemisia absinthium plant extract and application of antimicrobial activities," Journal of the Institute of Science and Technology, vol. 11, no. 1, pp. 365-375, 2021.

[36] G. K. Deokar and A. G. Ingale, "Green synthesis of gold nanoparticles (elixir of life) from banana fruit waste extract - an efficient multifunctional agent," RSC Advances, vol. 6, no. 78, pp. 74620-74629, 2016.

[37] H. Hamelian, S. Hemmati, K. Varmira, and H. Veisi, "Green synthesis, antibacterial, antioxidant and cytotoxic effect of gold nanoparticles using _Pistacia Atlantica_ extract," Journal of the Taiwan Institute of Chemical Engineers, vol. 93, pp. 21-30, 2018.

[38] M. F. Baran, H. Acay, and C. Keskin, "Determination of antimicrobial and toxic metal removal activities of plant-based synthesized (Capsicum annuum L. leaves), ecofriendly, gold nanomaterials. Global," Challenges, vol. 4, no. 5, article 1900104, 2020.

[39] K. Mapala and M. Pattabi, "Mimosa pudica flower extract mediated green synthesis of gold nanoparticles," NanoWorld Journal, vol. 3, no. 2, pp. 44-50, 2017.

[40] H. Shabestarian, M. Homayouni-Tabrizi, M. Soltani et al., "Green synthesis of gold nanoparticles using sumac aqueous extract and their antioxidant activity," Materials Research, vol. 20, no. 1, pp. 264-270, 2017.

[41] S. Raj, S. C. Mali, and R. Trivedi, "Green synthesis and characterization of silver nanoparticles using _Enicostemma axillare_ (Lam.) leaf extract," Biochemical and Biophysical Research Communications, vol. 503, no. 4, pp. 2814-2819, 2018.

[42] Shahed Behzadi, Vahid Serpooshan, Wei Tao et al., "Cellular uptake of nanoparticles: journey inside the cell," Process Biochemistry, vol. 46, no. 14, pp. 18-44, 2017.

[43] I. Mohammad, "Gold nanoparticle: an efficient carrier for MCP I of_Carica papaya_seeds extract as an innovative male contraceptive in albino rats," Journal of Drug Delivery Science and Technology, vol. 52, pp. 942-956, 2019.

[44] S. Vijayakumar, R. Vinayagam, M. A. Anand et al., "Green synthesis of gold nanoparticle using _Eclipta alba_ and its antidiabetic activities through regulation of Bcl-2 expression in pancreatic cell line," Journal of Drug Delivery Science and Technology, vol. 58, article 101786, 2020.

[45] S. C. Yang, C. H. Lin, I. A. Aljuffali, and J.-Y. Fang, "Current pathogenic Escherichia coli foodborne outbreak cases and therapy development," Archives of Microbiology, vol. 199, no. 6, pp. 811-825, 2017.

[46] M. Morais, A. L. Teixeira, F. Dias, V. Machado, R. Medeiros, and M. M. Priorjav, "Cytotoxic effect of silver nanoparticles synthesized by green methods in cancer," Journal of Medicinal Chemistry, vol. 63, no. 23, pp. 14308-14335, 2020.

[47] J. Wongpreecha, D. Polpanich, T. Suteewong, C. Kaewsaneha, and P. Tangboriboonrat, "One-pot, large-scale green synthesis of silver nanoparticles-chitosan with enhanced antibacterial activity and low cytotoxicity," Carbohydrate Polymers, vol. 199, pp. 641-648, 2018.

[48] M. K. Swamy, M. S. Akhtar, S. K. Mohanty, and U. R. Sinniah, "Synthesis and characterization of silver nanoparticles using fruit extract of _Momordica cymbalaria_ and assess- ment of their _in vitro_ antimicrobial, antioxidant and cytotoxicity activities," Spectrochimica Acta-Part A: Molecular and Biomolecular Spectroscopy, vol. 151, pp. 939-944, 2015.

[49] R. Zein, I. Alghoraibi, C. Soukkarieh, A. Salman, and A. Alahmad, "In-vitro anticancer activity against Caco-2 cell line of colloidal nano silver synthesized using aqueous extract of_Eucalyptus Camaldulensis_leaves," Heliyon, vol. 6, no. 8, article e04594, 2020.

[50] C. D. Fahrenholtz, J. Swanner, M. Ramirez-Perez, and R. N. Singh, "Heterogeneous responses of ovarian cancer cells to silver nanoparticles as a single agent and in combination with cisplatin," Journal of Nanomaterials, vol. 2017, 11 pages, 2017.

[51] S. Satpathy, A. Patra, B. Ahirwar, and M. Delwar Hussain, "Antioxidant and anticancer activities of green synthesized silver nanoparticles using aqueous extract of tubers of Pueraria tuberose," Artificial Cells, Nanomedicine and Biotechnology, vol. 46, no. 3, pp. 71-85, 2018. 